\title{
Work history, economic resources, and women's labour market withdrawal after the birth of the first grandchild
}

\author{
Francesca Zanasi ${ }^{1}\left[\right.$ D $\cdot$ Inge Sieben ${ }^{1} \cdot$ Wilfred Uunk ${ }^{2}$
}

Published online: 12 July 2019

(c) The Author(s) 2019

\begin{abstract}
Typically, grandmothers are actively involved in the lives of their grandchildren, most frequently as care providers. At the same time, these individuals become grandparents while still employed. These two roles-of active grandparent and worker-might conflict, since both demand time and energy. This study examines whether the birth of the first grandchild leads to labour market withdrawal for women, and whether there are differences between grandmothers according to their work history and household economic resources. We considered the work history of women both as a measure of work-family preferences and a source of opportunities and constraints to labour market behaviour later in life. Our analyses of data from the English Longitudinal Study of Ageing (ELSA) 2002-2017 using hybrid logistic models show that the probability of labour market withdrawal increases after the birth of the first grandchild. Women who had continuous working careers, or short employment interruptions, were more likely to withdraw from the labour market after the birth of the first grandchild than their counterparts with non-continuous careers, as well as women living in wealthy households. The explanation lies in the lower opportunity cost these women encounter in withdrawing from the labour market. Our findings relate to policies aimed at increasing retirement ages all over Europe, advocating that these measures could conflict with grandmothers' involvement in their grandchildren's lives.
\end{abstract}

Keywords Grandparenthood · Life course · Work history · Economic resources $\cdot$ Labour market withdrawal $\cdot$ English longitudinal study of ageing

\section{Introduction}

All over Europe, increased life expectancy makes it common for grandchildren to grow up while their grandparents are still alive, and research on the multifaceted role of grandparents has begun to proliferate (for a literature review, see

Responsible editor: Susanne Iwarsson.

Francesca Zanasi

f.zanasi@uvt.nl

Inge Sieben

i.j.p.sieben@uvt.nl

Wilfred Uunk

wilfred.uunk@uni-bamberg.de

1 Department of Sociology, TS Social and Behavioural Sciences, Tilburg University, Warandelaan 2, 5037 AB Tilburg, The Netherlands

2 Chair of Sociology I, Otto-Friedrich-Universität Bamberg, Feldkirchenstr. 21, 96052 Bamberg, Germany
Hank et al. 2018). Scholars have widely investigated the role of grandparents as childcare providers (Attias-Donfut et al. 2005; Hank and Buber 2009) whose positive externalities extend to at least two generations. On the one hand, grandparental care supports younger generations' employment (Dimova and Wolff 2011), especially in those institutional settings where formal childcare is rarely or narrowly provided (Bordone et al. 2017). On the other hand, becoming a grandparent is experienced as a highly positive life transition by individuals (Mahne and Motel-Klingebiel 2012). That is, spending time with grandchildren provides emotional gratification and a sense of belonging and usefulness, with positive effects on health and life satisfaction (Arpino and Bordone 2014; Mahne and Huxhold 2015; Di Gessa et al. 2016).

Scientific interest in grandparents has coincided with major policy reforms all over Europe aimed at raising pension ages (OECD 2017). Scholars have warned that keeping older workers in the labour market could conflict with their involvement in grandchildren's lives (Gray 2005), and that this involvement is related to early retirement 
preferences (Hochman and Lewin-Epstein 2013). Indeed, midlife individuals are likely to be in employment when they become grandparents, as all over Europe the transition to grandparenthood typically precedes retirement by at least 5 years (Leopold and Skopek 2015). In recent years, several cross-national studies in Europe have confirmed that becoming a grandparent (Van Bavel and De Winter 2013) and providing childcare (De Preter et al. 2013) are associated with early retirement. Single-country studies focusing on the USA, Sweden, and Austria reached similar conclusions (Lumsdaine and Vermeer 2015; Frimmel et al. 2017; Kridahl 2017; Rupert and Zanella 2018).

Our study focuses on England, where the work-grandchild conflict and its consequences for labour market participation have received relatively little attention, especially regarding women, who bear the burden of care responsibilities and are the most likely to provide grandchild care (Gray 2005). The English case is of interest for several reasons. Firstly, in England, grandparents, especially grandmothers, have a complementary role to formal childcare services (Wheelock and Jones 2002; Gray 2005). In England, childcare services are market provided, with state-funded places allocated through means-testing (Lewis and West 2017). The cost of childcare is among the highest in OECD countries, amounting to $26.6 \%$ of family income (OECD 2011). To increase maternal employment the state employs tax credits and subsidizes free hours of childcare for low-income families. Nevertheless, these measures do not fully account for families' childcare needs, especially for those families working non-standard hours. Moreover, they have been the target of recent austerity measures (Lewis and West 2017). Thus, over a third of English families rely on informal care, mainly provided by grandparents, against $20 \%$ of families in France and $0.1 \%$ in Denmark (OECD 2011). Secondly, English grandparents are expected to be economically active: early retirement solutions are not easily provided (Schils 2008) and the statutory pension age for women is rising rapidly from 60 to 65 , bringing it in line with the pension age for men. Finally, England has a contribution-based pension system (Schils 2008). Contributions to the basic state pension are acquired via years of employment, and individuals can opt into voluntary private pensions to supplement the basic state pension (Gardiner et al. 2015). As women's reproductive labour is often linked with discontinuous working careers, they have a limited opportunity to build up state, private, or occupational pensions, with consequences for their pension incomes in later life (Ginn and Arber 1996; Evandrou and Glaser 2003; Sefton et al. 2011; Gardiner et al. 2015) and retirement timing (Finch 2014). Thus, women's life courses and economic resources are crucial factors in both the attraction and feasibility of labour market withdrawal (LMW) after the birth of a grandchild.

\section{Study aim and hypotheses}

In this study, we focused on the relation between the birth of the first grandchild and midlife women's working careers, and specifically on the probability of their LMW. Moreover, we add to the existing literature by considering differences between grandmothers in terms of work histories and economic household situations.

When studying working histories, we adopted a life course approach. Deciding how to reconcile grandchild care provision with paid work depends on women's previous work-family history. Work-family histories could signal, on the one hand, persisting preferences for family or work (in a perspective we call "attachment hypothesis"), but, on the other hand, they could determine the economic affordability of LMW (in a perspective we call "opportunity cost") when women become grandmothers. When looking at household's economic situations, we adopted a couple perspective, considering that labour market decisions are taken in a family context. Underpinned by the theoretical background below, three hypotheses guided our analyses:

(1a) Compared to women with discontinuous working careers, women with continuous working careers are less likely to withdraw from the labour market after the birth of the first grandchild, due to persisting preferences for work over family.

(1b) Compared to women with discontinuous working careers, women with continuous working careers are more likely to withdraw from the labour market after the birth of the first grandchild, due to accumulation of pension contributions and economic independence.

(2) Compared to women from low-income households, women from high-income households are more likely to withdraw from the labour market after the birth of the first grandchild.

Grandmothers will already have had to make significant decisions about work and care at least once in their adult lives, around the birth of their own child(ren). They will have decided which strategies to implement in order to reconcile their work and family lives, such as delayed labour market entry, LMW, part-time working, or prolonged work. The adopted work-family strategy has distinct implications for the study of grandmothers' work decisions (Pienta et al. 1994; Hank 2004; Finch 2014).

On the one hand, we may assume that the priority given to work/family throughout one's working career is an indicator of work/family orientations. Research shows that women 
who continued to work during their childbearing period were more likely to be at work thereafter (Pienta et al. 1994; Hank 2004; Finch 2014). The same holds true for women postponing childbearing (Pienta 1999; Stafford et al. 2018). These studies used the so-called "attachment hypothesis" to explain the underlying mechanism. That is, in cases where women have invested in their personal attainment and human capital accumulation, they hold stronger ties to the labour market, leading to later retirement ages (Pienta 1999; Hank 2004). Hence, grandmothers may reproduce preferences and practices already put in place when they became mothers; those who have had a continuous working career could be less likely to withdraw from the labour market in the late stage of their career when they have grandchildren than women who had a discontinuous working career due to care responsibilities (Hypothesis 1a).

On the other hand, the decisions about paid work taken earlier in life, for example, around childbirth, contribute to economic independence and the accumulation of pension wealth; the years spent working have long-term consequences in terms of retirement eligibility and the economic affordability of LMW. Finch (2014) discussed the opportunity cost of retiring for those women who have had career breaks, usually experienced by women for care responsibilities, due to the resulting low levels of pension wealth. To receive the full state pension in England, individuals must either meet the state pension age or have paid a certain amount of National Insurance (NI) contributions. ${ }^{1}$ Individuals contributing for a lesser number of years receive a lower amount. Some workers have the option to maintain a private pension scheme, but this is rarely the case for women (Gardiner et al. 2015), which means that they are more often forced to rely on the flat-rate state pension alone. Additionally, the likelihood of receiving income from a private pension fund, and the amount received, is closely related to the individual's employment pattern (Ginn and Arber 1996). Therefore, women who have had a continuous working career might be more likely to withdraw from the labour market when they have a grandchild compared to women who have had a discontinuous working career (Hypothesis 1b), because LMW is feasible both economically and from the perspective of pension eligibility criteria.

When investigating the late-life career decisions of women, it is important to consider the role played by current economic resources at the household level. It is an additional way to investigate the opportunity cost of LMW for

\footnotetext{
1 The flat-rate pension consisting of $£ 122.30$ (around $€ 104$ ) per week applies to individuals who reach the state pension age before the 6 April 2016. Regarding pension contributions, individuals born after April 1950 need a total of 30 qualifying years of NI contributions; women born before that date need 39 years of employment to receive a full state pension.
}

women, because it includes all resources available in the household. A large body of literature shows that, in many European countries, a husband's elevated occupational position is related to a reduction in a wife's work commitment, mainly due to an increased specialization of tasks between the spouses (Blossfeld and Drobnič 2001). So, even women who did not themselves accumulate economic resources and pension wealth might consider LMW as a viable option when they are part of a high-income household. Total family income can thus make up for a lack of economic independence or an inability to meet the eligibility criteria for retirement. Thus, women who are part of high-income households could be more likely to withdraw from the labour market when they have grandchildren than their economically less advantaged counterparts (Hypothesis 2).

\section{Material and method}

\section{Data}

We employed the first eight waves of the English Longitudinal Study of Ageing (ELSA) 2002-2017, which is a biannual panel study on health, economic position, and quality of life among individuals older than 50 and their partners, living in private households (Marmot et al. 2018). ${ }^{2} \mathrm{We}$ selected women between 50 and 65 years old and excluded those who had never done paid work and/or were childless. Furthermore, only those respondents who participated in wave 3 (containing information on previous life course) were included in the sample. After these restrictions and excluding observations with missing values in the variables of interest, the final sample comprised 2366 women and 10,207 person-wave observations (average 4.4 observations per individual).

\section{Variables}

The dependent variable was dichotomous, capturing whether the individual was not in paid work and based on self-report to be economically inactive (looking after home/family) or formally retired.

The main independent variable was the birth of the first grandchild. In fact, research shows that first-born or only children more often receive grandparental childcare than second or subsequent children (Fergusson et al. 2008). The respondents were asked to report on the number of grandchildren they had, and from this we created a dummy

\footnotetext{
${ }^{2}$ Ethical approval for all the ELSA waves is granted by the NHS Research Ethics Committees under the National Research and Ethics Service (NRES).
} 
variable that was equal to (1) if the number of grandchildren changed from 0 to 1 between two waves. This strategy was successfully used by other scholars (e.g. Lumsdaine and Vermeer 2015), since information on the date of birth of the oldest grandchild was not available. ${ }^{3}$

The moderating variables capturing women's work history and economic resources did not vary across waves. To operationalize women's work history, we performed sequence analysis (see "Method" and "Analytical approach" sections below) on retrospective information collected in wave 3 . This led to the identification of four groups of women according to their work history between ages 18 and 45: (1) women who had largely continuous working careers, with a maximum 1 year not in paid work, e.g. on maternity leave; (2) women who had short (1-5 years) employment interruptions for family-related reasons; (3) women who had long (6-27 years) employment interruptions for familyrelated reasons; and (4) a residual category of women with employment interruptions for other reasons.

Current economic resources were measured by the yearly income of the household at the baseline. In this way, we made sure that this moderating variable was not sensitive to moves in/outside the labour market. The measure was adjusted against the Retail Price Index (RPI) of 2015. The variable was at the couple level and included individual and spouse earnings, family capital income (self-employment earnings, rental income from property, interest income from financial assets), individual and spouse private pensions or annuities from employers, individual and spouse incomes from public pensions (old age, disability), and other government transfers (veteran benefits, welfare benefits, worker's compensation benefits, unemployment benefits). We divided respondents into three groups, identified by income terciles calculated on the income distribution of the year the individual was observed for the first time in the sample. ${ }^{4}$

We included a set of control variables. Among timevarying variables, we included age (in categories), which is strongly related to the transition to both grandparenthood and retirement, and partner's work status (not married, partner not employed, partner employed, partner of other status) as spouses tend to synchronize retirement (Henretta et al. 1993), and having a partner is related to higher family

\footnotetext{
3 Information about the age of the oldest grandchild was available in the last wave released (8) of the ELSA survey. For those individuals' in analytical sample who also participated in wave $8(n=1753)$, we used retrospective information about the date of birth of the first grandchild and date of retirement. Results point the same way.

4 The cut-off points for each yearly family income distribution were (in Euros): 23,087 and 39,834 for 2002/2003, 36,778 and 53,786 for $2004 / 2005,27,006$ and 49,355 for $2006 / 2007,34,050$ and 52,849 for 2008/2009, 33,219 and 51,625 for 2010/2011, 31,199 and 51,322 for $2012 / 2013$.
}

income (Finch 2014). As an enabling factor for grandparental care (Gray 2005; Hank and Buber 2009), we measured the proximity of residence with a dummy variable indicating whether the woman had weekly contact with any of her children in person, and subjective health status (good, fair, bad). Finally, we included life course time-constant characteristics: educational level (less than college, some college, or another kind of qualification), as an additional indication of women's labour market attachment; birth cohort (before/ after 1950), capturing different retirement regulations; number of children, because the greater the number of children, the greater the (eventual) work interruptions as well as the adult children's need of support; and age at motherhood, because it is related to the timing of retirement and grandparenthood.

\section{Analytical approach}

As mentioned in "Variables" section, we performed sequence analysis to operationalize the work history variable, relying on retrospective information from wave 3 . Respondents were asked the start and end date of each of their employment spells, as well as their status between them. From this information, each year in the life of each respondent was assigned to a certain state, namely persistence in school, gap between school and work (i.e. delayed entry in employment), employment, economic inactivity for family-related reasons (including maternity leave), and a final category with other states (e.g. prison, disability, unemployment, travelling). After the identification of the individual life sequences, Optimal Marching Analysis (OMA) was used to compute a matrix of dissimilarities between pairs of sequences that served as input for cluster analysis (Abbott and Tsay 2000). The costs of substitution set to build the matrix were based on the transition probabilities between statuses empirically observed in the data.

The clustering procedure (with Ward's algorithm) provided standard goodness of fit statistics (Calinski Harabasz pseudo-F statistics and Duda Hart pseudo-T-squared), which made us decide on a four-cluster solution: women (1) with continuous careers; (2) with short employment interruptions (regardless of the reason of interruption); (3) with long employment interruptions for family-related reasons; and (4) with long employment interruptions for other reasons. We slightly altered the clusters to have a theoretically informed categorization of women. In particular, we aimed at clearly distinguishing women's work histories on the basis of the reason for employment interruptions. Firstly, in cluster (1) we retained only women who had employment interruptions shorter than or equal to one year, for example maternity leave or short unemployment spells. Secondly, the cut-off point between short and long employment interruptions was set to 5 years, which is the age children begin compulsory 
education and are less in need of childcare. Thirdly, in cluster (2) we included only women with short employment interruptions for family-related reasons. Finally, concerning women in cluster (2) and cluster (3) who experienced both short employment interruptions for family-related reasons and for other reasons, we included only women who also had up to 2 years of employment interruptions for other reasons, and moved women with other kinds of career trajectories into cluster (4).

To investigate the relation between the transition into grandparenthood and the transition out of the labour market, we used between-within random effects logistic models, also called hybrid models (Allison 2009; Schunck 2013). This analytical strategy offers the advantages of fixed-effects models, allowing the decomposition of the between- and within- individual effects for time-varying covariates. At the same time, it has a more flexible setup, also estimating the coefficients for variables that do not vary within individuals, such as the variables work history and total family income. In this study, we decomposed the time-varying predictor "first grandchild born" into two parts: the individual's mean value over time (between-individual component) and the deviation from this person-specific mean (within-individual component). The within-individual component was based on changes over time and resembled estimates of individual fixed-effects models. The score compared the outcome before/after a change in predictor, based on observations belonging to the same individual. In our case, it showed the difference in log-odds of LMW before and after having a grandchild for the same person, namely how becoming a grandmother was associated with LMW. In addition, the between-individual component accounted for all unobserved time-constant individual characteristics. In other words, it captured all those unobserved variables correlated with grandparenthood that were also correlated with LMW. The score was based on the comparison between women who were already grandmothers and women who were not, namely whether grandmothers, when compared to non-grandmothers, were more likely to withdraw from the labour market.

Since in logistic regression models it is problematic to interpret log-odds ratios (Mood 2010), for each model we presented the results in terms of average marginal effects (AMEs), namely the average differences in probability of LMW between the categories of the variables of interest. We set the statistical significance level at $p<0.05$. The statistical analyses were carried out with Stata 14 software (StataCorp 2015).

\section{Results}

Table 1 shows the characteristics of the sample. A good third of the women $(33 \%)$ were already outside the labour force (of which $17 \%$ were retired and $16 \%$ looking after home or family) at the beginning of the observation window, and just over half $(53 \%)$ of them were already grandmothers when they entered the survey. As to events occurring within the observation window, $24 \%$ of the women became grandmothers for the first time, and $43 \%$ recorded at least one transition out of paid employment.

In Table 2, we report the results of between-within random effects logistic analyses. Model 1 shows how the birth of the first grandchild related to LMW when all control variables were added. The coefficient based on the within-individual component (0.77) was statistically significant, while the between-individual component was not. ${ }^{5}$ This means that becoming a grandmother was positively related to LMW, but being a grandmother was not. The AME to be outside the labour market within women, namely before and after the first grandchild was born, was around 8 percentage points.

Model 2 adds the interaction term between the grandchild variables (both within and between components) and women's work history. We found a statistically significant relation between the transition to grandparenthood (within component) and LMW for women who had long employment interruptions for family-related reasons or employment interruptions for other reasons, compared to women with continuous careers, the reference category. No statistically significant difference was found between women who had short employment interruptions and women with continuous working careers. Similarly, Model 3 estimated the interaction effect of total family income and the first grandchild's birth. The interaction term showed a statistically significant, positive relation between the transition to grandparenthood (within component) and LMW for women who belonged to the third tercile of the income distribution compared to women from the first income tercile, the reference category. To the contrary, there was not a statistically significant difference between women belonging to the second and the first income tercile.

Figure 1 displays the AMEs for the probability of being outside the labour market within women after the first grandchild's birth, according to work history (from Model 2, left panel in Fig. 1) and total family income (from Model 3, right panel in Fig. 1). Having continuous careers or careers with short interruptions increased the probability of LMW for women after their first grandchild's birth by around 15 percentage points. On the other

\footnotetext{
$\overline{5}$ The Wald test of equality of coefficients (based on Chi-square test) shows that the within and between estimates are different $(p<0.05)$.
} 
Table 1 Characteristics of the sample, $n$ (individuals) $=2366$ and $N$ (observations) $=10,207$

\begin{tabular}{|c|c|c|c|c|}
\hline Variable & Category & At survey entry & $\%$ & $N$ \\
\hline \multirow[t]{3}{*}{ Work status } & Not in labour force & 797 & 33 & 4257 \\
\hline & Other statuses & 1569 & 67 & 5950 \\
\hline & $\begin{array}{l}\text { Women who withdrew } \\
\text { from LM during obser- } \\
\text { vation period }\end{array}$ & 1008 & 43 & \\
\hline \multirow[t]{3}{*}{ Grandchild } & No grandchild born & 1117 & 47 & 3795 \\
\hline & First grandchild born & 1249 & 53 & 6412 \\
\hline & $\begin{array}{l}\text { Women who became } \\
\text { grandmother during } \\
\text { observation period }\end{array}$ & 563 & 24 & \\
\hline \multirow[t]{4}{*}{ Work history } & Continuous & 488 & 21 & 2157 \\
\hline & Short interruptions & 456 & 19 & 2015 \\
\hline & Long interruptions & 994 & 42 & 4290 \\
\hline & Other & 428 & 18 & 1745 \\
\hline \multirow[t]{3}{*}{ Total family income } & 1st tercile & 790 & 33 & 3129 \\
\hline & 2nd tercile & 790 & 34 & 3376 \\
\hline & 3rd tercile & 786 & 33 & 3702 \\
\hline \multirow[t]{3}{*}{ Age } & $50 / 55$ & 1401 & 59 & 2818 \\
\hline & $56 / 60$ & 529 & 22 & 3611 \\
\hline & $61 / 65$ & 436 & 19 & 3778 \\
\hline \multirow[t]{3}{*}{ Educational level } & Less than college & 1368 & 58 & 5805 \\
\hline & Some college & 816 & 34 & 3662 \\
\hline & Else & 182 & 8 & 740 \\
\hline \multirow[t]{4}{*}{ Partner's work status } & No partner & 572 & 24 & 2441 \\
\hline & Partner employed & 1059 & 45 & 4006 \\
\hline & Partner not employed & 451 & 19 & 2645 \\
\hline & Partner other status & 284 & 12 & 1115 \\
\hline \multirow[t]{2}{*}{ Birth cohort } & Before 1950 & 1376 & 58 & 5130 \\
\hline & After 1950 & 990 & 42 & 5077 \\
\hline \multirow[t]{2}{*}{ Weekly contact with children } & No & 529 & 22 & 2902 \\
\hline & Yes & 1837 & 78 & 7305 \\
\hline Subjective health (good/bad) & Mean (sd) & $0.26(0.54)$ & & \\
\hline Number of children & Mean (sd) & $2.46(1.25)$ & & \\
\hline Age at motherhood & Mean (sd) & $24.2(5.13)$ & & \\
\hline Total observations & & & & 10,207 \\
\hline Total unique women & & 2366 & & \\
\hline
\end{tabular}

hand, having long employment interruptions for familyrelated reasons only slightly increased the probability of LMW, and no increase was discernible for women with careers interrupted for other reasons. Turning to total family income, women living in households belonging to the third income tercile were roughly 14 percentage points more likely to withdraw from the labour market after the first grandchild was born, while there was no statistically significant relation between becoming a grandmother and LMW for women belonging to the first and second income terciles.

\section{Discussion}

In this study, we investigated how the birth of the first grandchild relates to grandmothers' LMW in England by employing recent panel data from the ELSA survey (2002-2017). Our main contribution was the adoption of a life course perspective, central in the research on ageing (Bengtson et al. 2005), because it implies the understanding of late-life events as resulting from the interaction between work history and present contingencies, in 
Table 2 Hybrid models for the probability of LMW, $n$ (individuals) $=2366$ and $N$ (observations) =10,207

\begin{tabular}{|c|c|c|c|c|c|c|c|c|c|}
\hline \multirow[t]{2}{*}{ Variable } & \multicolumn{3}{|l|}{ Model 1} & \multicolumn{3}{|l|}{ Model 2} & \multicolumn{3}{|l|}{ Model 3} \\
\hline & Coeff. & & SE & Coeff. & & $\mathrm{SE}$ & Coeff. & & SE \\
\hline \multicolumn{10}{|l|}{ First grandchild born } \\
\hline Grandchild—within (W) & 0.770 & $* * *$ & 0.163 & 1.431 & $* * *$ & 0.384 & 0.114 & & 0.311 \\
\hline Grandchild—between (B) & 0.251 & & 0.215 & 0.960 & $*$ & 0.402 & 0.192 & & 0.341 \\
\hline \multicolumn{10}{|l|}{ Work history } \\
\hline \multicolumn{10}{|l|}{ Continuous career (reference) } \\
\hline Short interruptions & 0.275 & & 0.226 & 0.666 & & 0.410 & 0.273 & & 0.226 \\
\hline Long interruptions & 1.228 & $* * *$ & 0.196 & 1.750 & $* * *$ & 0.357 & 1.229 & $* * *$ & 0.197 \\
\hline Other & 2.195 & $* * *$ & 0.239 & 2.995 & $* * *$ & 0.412 & 2.188 & $* * *$ & 0.239 \\
\hline \multicolumn{10}{|l|}{ Total family income } \\
\hline \multicolumn{10}{|l|}{ 1st tercile (reference) } \\
\hline 2nd tercile & -0.621 & $* * *$ & 0.182 & -0.640 & $* * *$ & 0.183 & -0.783 & $*$ & 0.369 \\
\hline 3rd tercile & -0.685 & $* * *$ & 0.196 & -0.710 & $* * *$ & 0.197 & -0.697 & $*$ & 0.344 \\
\hline \multicolumn{10}{|l|}{ Interaction terms } \\
\hline Grandchild $(\mathrm{W}) \times$ short interruptions & & & & 0.142 & & 0.543 & & & \\
\hline Grandchild $(\mathrm{W}) \times$ long interruptions & & & & -0.967 & $*$ & 0.433 & & & \\
\hline Grandchild $(\mathrm{W}) \times$ other & & & & -1.327 & $*$ & 0.539 & & & \\
\hline Grandchild $(B) \times$ short interruptions & & & & -0.649 & & 0.539 & & & \\
\hline Grandchild $(B) \times$ long interruptions & & & & -0.798 & & 0.465 & & & \\
\hline Grandchild $(\mathrm{B}) \times$ other & & & & -1.272 & $*$ & 0.541 & & & \\
\hline Grandchild $(\mathrm{W}) \times 2$ nd tercile & & & & & & & 0.380 & & 0.399 \\
\hline Grandchild $(\mathrm{W}) \times 3$ rd tercile & & & & & & & 1.233 & $* *$ & 0.391 \\
\hline Grandchild $(B) \times 2$ nd tercile & & & & & & & 0.226 & & 0.444 \\
\hline Grandchild $(\mathrm{B}) \times 3$ rd tercile & & & & & & & -0.045 & & 0.428 \\
\hline \multicolumn{10}{|l|}{ Age } \\
\hline \multicolumn{10}{|l|}{$50 / 55$ (reference) } \\
\hline $56 / 60$ & 0.778 & $* * *$ & 0.104 & 0.790 & $* * *$ & 0.105 & 0.777 & $* * *$ & 0.105 \\
\hline $61 / 65$ & 3.403 & $* * *$ & 0.136 & 3.408 & $* * *$ & 0.136 & 3.405 & $* * *$ & 0.136 \\
\hline \multicolumn{10}{|l|}{$\begin{array}{l}\text { Educational level } \\
\text { (less than) high school }\end{array}$} \\
\hline Some college & -0.196 & & 0.163 & -0.195 & & 0.163 & -0.195 & & 0.163 \\
\hline Else & -0.628 & $*$ & 0.270 & -0.630 & $*$ & 0.271 & -0.631 & $*$ & 0.271 \\
\hline \multicolumn{10}{|l|}{ Partner's work status } \\
\hline \multicolumn{10}{|l|}{ No partner (reference) } \\
\hline Partner employed & -0.042 & & 0.166 & -0.036 & & 0.166 & -0.046 & & 0.166 \\
\hline Partner not employed & 1.785 & $* * *$ & 0.167 & 1.791 & $* * *$ & 0.167 & 1.771 & $* * *$ & 0.167 \\
\hline Partner other status & 0.830 & $* * *$ & 0.184 & 0.842 & $* * *$ & 0.185 & 0.815 & $* * *$ & 0.185 \\
\hline Birth cohort (born after 1950) & -1.303 & $* * *$ & 0.159 & -1.297 & $* * *$ & 0.159 & -1.308 & $* * *$ & 0.159 \\
\hline Weekly contact with children (yes) & -0.106 & & 0.102 & -0.105 & & 0.102 & -0.116 & & 0.102 \\
\hline Subjective health (bad) & -0.052 & & 0.087 & -0.044 & & 0.087 & -0.056 & & 0.087 \\
\hline Number of children & 0.033 & & 0.073 & 0.044 & & 0.073 & 0.033 & & 0.073 \\
\hline Age at motherhood & 0.020 & & 0.018 & 0.024 & & 0.018 & 0.020 & & 0.018 \\
\hline Constant & -2.865 & $* * *$ & 0.391 & -3.372 & $* * *$ & 0.455 & -2.797 & $* * *$ & 0.435 \\
\hline Log-likelihood & -4358.94 & & & -4349.73 & & & -4352.93 & & \\
\hline
\end{tabular}

$* * * p<0.001, * * p<0.01, * p<0.05$

our case the birth of the first grandchild. Moreover, we accounted for the fact that labour market decisions are not made in a vacuum, but in a family context (De Preter et al.
2015). That is, current economic resources at the family level could moderate the association between the birth of the first grandchild and LMW. Our results show that the 

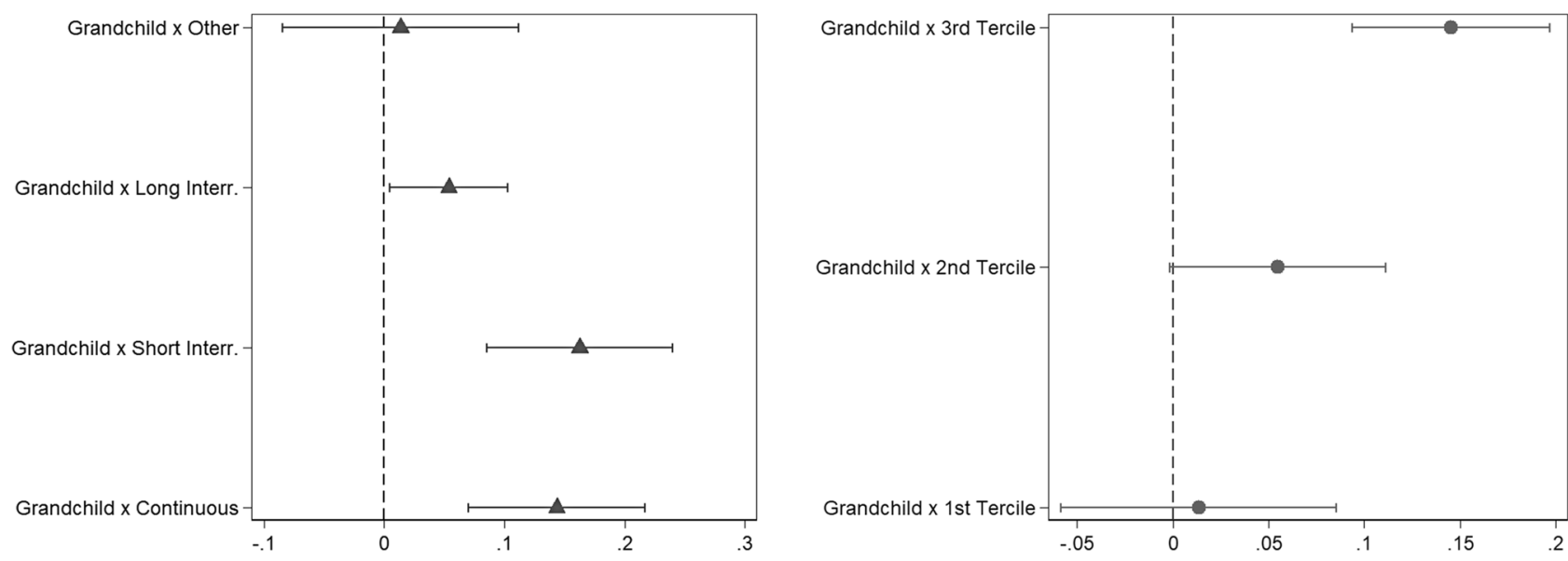

Fig. 1 Difference in probability of withdrawing from the labour market before/after the birth of a grandchild, by work history (left panel, triangles) and total family income (right panel, dots). 95\% Confidence intervals. $n$ (individuals) $=2366$ and $N$ (observations) $=10,207$

birth of the first grandchild increases the probability of LMW, but differences exist according to grandmothers' characteristics.

We found confirmation of the "opportunity cost" perspective, namely the idea that privileged women, both in terms of their own working careers and their household resources, are those who can most easily afford LMW upon the arrival of a grandchild. Firstly, the birth of the first grandchild increases the probability of LMW for women with continuous working careers, or with short employment interruptions, confirming our Hypothesis $1 \mathrm{~b}$ instead of Hypothesis 1a (the "attachment hypothesis"). The amount of time spent not working in these cases has been short enough to avoid resulting in disadvantages in later life, in terms of pension wealth, and they have been able to withdraw to a larger extent when becoming grandmothers. However, this result should be interpreted with caution, because the $95 \%$ confidence intervals partially overlap.

Secondly, the birth of the first grandchild raises the probability of LMW for women belonging to high-income families, which is not the case for women from low-income households, confirming our Hypothesis 2. This result is in line with previous studies showing that grandparents providing child care are usually more wealthy (Wheelock and Jones 2002; Gray 2005; Glaser et al. 2013). For this category of women, choosing to withdraw from the labour market after the birth of a grandchild does not result in a high opportunity cost, even if it could lead, for example, to a reduced state pension income. It could be that living with a wealthy partner makes up for eventual foregone earnings caused by LMW. In fact, individual labour market behaviour involves the family as a unit, especially when it comes to women, whose labour market trajectories are strongly intertwined with family responsibilities and the husband's resources (Henretta et al. 1993; Blossfeld and Drobnič 2001).
This study presents some limitations that ought to be addressed. Firstly, the dependent variable captured selfreported employment status, regardless of the number of hours worked. We are aware of the fact that women could decide to reduce their working hours, instead of dropping out of work altogether, after the grandchild's birth (see, for example, Rupert and Zanella 2018). Moreover, we did not distinguish between full-time and part-time work with regard to our main moderating variable tapping women's working history. Our choice is justified by ongoing pension reforms raising pension age (OECD 2017) and thus the urge to understand whether family dynamics could conflict with extended working lives. Surely, this is an interesting and relevant direction for future research. Adjustments in terms of working hours for midlife women could be investigated in the light of (eventual) transitions to part-time work experienced around motherhood. This would further refine the life course approach and the operationalization of the "attachment hypothesis" and "opportunity costs" perspective. Secondly, we were unable to include more detailed measures of the life history of the respondents, such as the kinds of jobs they held. This information, not present in the data, could provide additional insights into the socioeconomic positions of women, further disentangling the constraints and opportunities surrounding LMW. We suggest this as an additional direction for further research, to better understand how inequalities during the life course impact later life, especially around the birth of a grandchild. Finally, it could be argued that adult children adjust their fertility intentions on grandparental availability, in the sense that the grandchild's birth occurs once the grandparents are retired. This is the case for Italy (Battistin et al. 2014) and for second-order births in the Netherlands (Thomese and Liefbroer 2013). Similar evidence is lacking for England, but studies have pointed out 
that grandparenthood precedes British women's LMW by 7 years (Leopold and Skopek 2015). Hence, we believe our study to be well grounded in the field of the consequences of work-family conflict. Further investigation of this reverse relationship, namely how LMW affects the transition to grandparenthood, could shed light on the multiple consequences of rising pension age in terms of fertility.

This article adds England to the collection of single-country studies showing the relationship between the birth of grandchildren and labour market adjustments, which include Austria (Frimmel et al. 2017), Sweden (Kridahl 2017), and the USA (Lumsdaine and Vermeer 2015; Rupert and Zanella 2018). The overlap between grandparenthood and employment is conflictual for midlife individuals living in highly heterogeneous welfare settings, who share the desire to early retire to spend more time with their grandchildren (Hochman and Lewin-Epstein 2013). Thus, the conclusions of the present study go beyond the English context and resonate with several voices advocating for caution in raising the retirement age (see, for example, Glaser et al. 2013). In settings that lack a universal provision of childcare services, keeping older workers in the labour market could lead, over time, to childcare gaps for working parents (Gray 2005; Glaser et al. 2013). Moreover, our study suggests that pension reforms might be effective only in keeping economically worse off grandmothers on the labour market, while better-off women are able to afford retirement or economic inactivity. Lowincome families might find simultaneous difficulties in relying on market-provided childcare services and on their older mothers, who are unable to give up their work commitments. In countries such as Sweden, where formal childcare services are universally provided, and grandparental childcare is not driven by need (Igel and Szydlik 2011), grandparents still give up their work commitment (Kridahl 2017). Thus, policies aimed at increasing the labour market participation of older workers are not guaranteed to be effective and may not mitigate financial losses for those aiming to enact the grandparental role. In conclusion, grandmothers should not be overlooked in family policy-making, to ensure that involvement in grandchildren's lives is not the privilege of a few, and to avoid negative effects on labour market participation and pension wealth.

Acknowledgements The authors thank Gateway to Global Aging Data for the harmonized version of the ELSA study and the participants in the III South Tyrol Workshop on Intergenerational Relationships for comments on an early version of the manuscript. We owe gratitude to dr. Gabriele Mari who provided insight and expertise that greatly improved the paper.

\section{Compliance with ethical standards}

Conflict of interest The authors declare that they have no conflict of interest.
Open Access This article is distributed under the terms of the Creative Commons Attribution 4.0 International License (http://creativeco mmons.org/licenses/by/4.0/), which permits unrestricted use, distribution, and reproduction in any medium, provided you give appropriate credit to the original author(s) and the source, provide a link to the Creative Commons license, and indicate if changes were made.

\section{References}

Abbott A, Tsay A (2000) Sequence analysis and optimal matching methods in sociology. Sociol Methods Res 29:3-33

Allison P (2009) Fixed effects regression models. SAGE, Thousand Oaks

Arpino B, Bordone V (2014) Does grandparenting pay off? the effect of child care on grandparents' cognitive functioning. J Marriage Fam 76:337-351

Attias-Donfut C, Ogg J, Wolff FC (2005) European patterns of intergenerational financial and time transfers. Eur J Ageing 2:161-173

Battistin E, De Nadai M, Padula M (2014) Roadblocks on the road to grandma's house: fertility consequences of delayed retirement. IZA DP No. 8071, pp 2-46

Bengtson V, Elder GHJ, Putney NM (2005) The life course perspective on ageing: linked lives, timing, and history. In: Johnson ML (ed) The Cambridge handbook of age and ageing. Cambridge, Cambridge, pp 9-17

Blossfeld H-P, Drobnič S (2001) Careers of couples in contemporary societies: from male-breadwinner to dual-earner families. Oxford University Press, Oxford

Bordone V, Arpino B, Aassve A (2017) Patterns of grandparental child care across Europe: the role of the policy context and working mothers' need. Ageing Soc 37:845-873

De Preter H, Van Looy D, Mortelmans D (2013) Individual and institutional push and pull factors as predictors of retirement timing in Europe: a multilevel analysis. J Aging Stud 27:299-307

De Preter H, Van Looy D, Mortelmans D (2015) Retirement timing of dual-earner couples in 11 European countries? a comparison of cox and shared frailty models. J Fam Econ Issues 36:396-407

Di Gessa G, Glaser K, Tinker A (2016) The impact of caring for grandchildren on the health of grandparents in Europe: a lifecourse approach. Soc Sci Med 152:166-175

Dimova R, Wolff FC (2011) Do downward private transfers enhance maternal labor supply? evidence from around Europe. J Popul Econ 24:911-933

Evandrou M, Glaser K (2003) Combining work and family life: the pension penalty of caring. Ageing Soc 23:583-601

Fergusson E, Maughan B, Golding J (2008) Which children receive grandparental care and what effect does it have? J Child Psychol Psychiatry 2:161-169

Finch N (2014) Why are women more likely than men to extend paid work? the impact of work-family life history. Eur J Ageing 11:31-39

Frimmel W, Halla M, Schmidpeter B, Winter-Ebmer R (2017) Grandmothers' labor supply. ISER Work Pap Ser 1-36

Gardiner J, Robinson AM, Fakhfakh F (2015) Exploring the private pension gender gap and occupation in later working life. Work Employ Soc 30:687-707

Ginn J, Arber S (1996) Patterns of employment, gender and pensions: the effect of work history on older women's non-state pensions. Work Employ Soc 10:469-490

Glaser K, Price D, Ribe Montserrat E, et al (2013) Grandparenting in Europe: family policy and grandparents' role in providing childcare. Grandparents Plus, London 
Gray A (2005) The changing availability of grandparents as carers and its implications for childcare policy in the UK. J Soc Policy 34:557-577

Hank K (2004) Effects of early life family events on women's late life labour market behaviour: an analysis of the relationship between childbearing and retirement in Western Germany. Eur Sociol Rev 20:189-198

Hank K, Buber I (2009) Grandparents caring for their grandchildren. J Fam Issues 30:53-73

Hank K, Cavrini G, Di Gessa G, Tomassini C (2018) What do we know about grandparents? insights from current quantitative data and identification of future data needs. Eur J Ageing 15:1-11

Henretta JC, O'Rand AM, Chan CG (1993) Joint role investments and synchronization of retirement: a sequential approach to couples' retirement timing. Soc Forces 71:981-1000

Hochman O, Lewin-Epstein N (2013) Determinants of early retirement preferences in Europe: the role of grandparenthood. Int J Comp Sociol 54:29-47

Igel C, Szydlik M (2011) Grandchild care and welfare state arrangements in Europe. J Eur Soc Policy 21:210-224

Kridahl L (2017) Retirement timing and grandparenthood in Sweden: evidence from population-based register data. Demogr Res 37:957-994

Leopold T, Skopek J (2015) The demography of grandparenthood: an international profile. Soc Forces 94:801-832

Lewis J, West A (2017) Early childhood education and care in england under austerity: continuity or change in political ideas, policy goals, availability, affordability and quality in a childcare market? J Soc Policy 46:331-348

Lumsdaine RL, Vermeer SJC (2015) Retirement timing of women and the role of care responsibilities for grandchildren. Demography $52: 433-454$

Mahne K, Huxhold O (2015) Grandparenthood and subjective wellbeing: moderating effects of educational level. J Gerontol B Psychol Sci Soc Sci 70:782-792

Mahne K, Motel-Klingebiel A (2012) The importance of the grandparent role-A class specific phenomenon? Evidence from Germany. Adv Life Course Res 17:145-155

Marmot M, Oldfield Z, Clemens S et al (2018) English longitudinal study of ageing: waves $0-8,1998-2017$. [data collection]. 28th Edition
Mood C (2010) Logistic regression: why we cannot do what we think we can do, and what we can do about it. Eur Sociol Rev 26:67-82

OECD (2011) Doing better for families. OECD Publishing, Paris

OECD (2017) Pensions at a Glance 2017: OECD and G20 Indicators. OECD Publishing, Paris

Pienta A (1999) Early childbearing patterns and women's labor force behavior in later life. J Women Aging 11:69-84

Pienta A, Burr JA, Mutchler JE (1994) Women's labor force participation in later life: the effects of early work and family experiences. J Gerontol 49:S231-S239

Rupert P, Zanella G (2018) Grandchildren and their grandparents' labor supply. J Public Econ 159:89-103

Schils T (2008) Early retirement in Germany, the Netherlands, and the United Kingdom: a longitudinal analysis of individual factors and institutional regimes. Eur Sociol Rev 24:315-329

Schunck R (2013) Within and between estimates in random-effects models: advantages and drawbacks of correlated random effects and hybrid models. Stata J 13:65-76

Sefton T, Evandrou M, Falkingham J (2011) Family ties: women's work and family histories and their association with incomes in later life in the UK. J Soc Policy 40:41-69

Stafford M, Lacey R, Murray E et al (2018) Work-family life course patterns and work participation in later life. Eur J Ageing 16:1-12

StataCorp (2015) Stata statistical software: release 14, College Station, TX, StataCorp LP

Thomese F, Liefbroer AC (2013) Child care and child births: the role of grandparents in the Netherlands. J Marriage Fam 75:403-421

Van Bavel J, De Winter T (2013) Becoming a grandparent and early retirement in Europe. Eur Sociol Rev 29:1295-1308

Wheelock J, Jones K (2002) 'Grandparents are the next best thing': informal childcare for working parents in Urban Britain. J Soc Policy 31:441-463

Publisher's Note Springer Nature remains neutral with regard to jurisdictional claims in published maps and institutional affiliations. 